\title{
Acute Myocardial Infarction and Allergy, Causal or Casual
}

\section{Relationship?}

José I. Morgado Garcia-Polavieja ${ }^{1 *}$, Margarita Castillo Paredes ${ }^{2}$, Enrique López Herrero², Francisco Javier Fernández López ${ }^{3}$, Ana Blanca Paloma Martínez Pérez ${ }^{1}$, José Francisco Díaz Fernández ${ }^{1}$

${ }^{1}$ Cardiology Department. Juan Ramon Jimenez University Hospital, Huelva, Spain.

${ }^{2}$ Internal Medicine Department. Juan Ramon Jimenez University Hospital, Huelva, Spain.

${ }^{3}$ Emergency Department. Juan Ramon Jimenez University Hospital, Huelva, Spain.

*Corresponding Author: José I. Morgado Garcia-Polavieja. Cardiology Department Juan Ramon Jimenez University Hospital (Huelva, Calle Austria Bloque 4 bajo C Seville (Spain)

Received Date: April 27, 2021; Accepted Date: May 31, 2021; Published Date: June 07, 2021

Citation: José I. Morgado Garcia-Polavieja, Margarita Castillo Paredes, Enrique López Herrero, Francisco Javier Fernández López, Ana Blanca Paloma Martínez Pérez. et al. (2021) Acute Myocardial Infarction and Allergy, Causal or Casual Relationship?. J. Clinical Cardiology and Cardiovascular Interventions, 4(12); Doi:10.31579/2641-0419/175

Copyright: @ 2021 José I. Morgado Garcia-Polavieja, This is an open-access article distributed under the terms of the Creative Commons Attribution License, which permits unrestricted use, distribution, and reproduction in any medium, provided the original author and source are credited.

\begin{abstract}
A 53-year-old man with a known allergy to metamizole presented for acute gonalgia, receiving metamizole by mistake. He suffers a severe allergy reaction accompanied by chest pain and signs of acute lower myocardial infarction, which subsides with treatment of anaphylactic shock and fibrinolysis, without observing intracoronary thrombus or signs of complication of atherosclerotic plaque.

Key words: kounis syndrome; allergic myocardial infarction; myocardial infarction with normal coronary arteries
\end{abstract}

\section{LEARNING OBJECTIVE}

An exceptional clinical case is presented illustrating an acute myocardial infarction related to a severe allergic reaction. In addition, a review of the optimal management of this entity is carried out. We intend to make this entity known, which should be suspected in the appropriate clinical setting

\section{Introduction}

A 53-year-old man with a prior known allergic reaction to metamizole, with no relevant medical history, who attended the emergency department due to knee pain. He received, by mistake, an injection of metamizole, suffering a picture compatible with anaphylactic shock, in addition to chest pain.

The physical examination revealed a poor general condition, BP 70/40 mm Hg, HR: $115 \mathrm{bpm}$, poorly perfused with elongated capillary filling, tachypneic, diaphoretic, generalized erythema. The presence of uvular edema and a long expiration, with wheezing, stood out.

A series of complementary tests were performed, which are detailed below: electrocardiogram showing ascending of the ST on the inferior face (PICTURE 1).

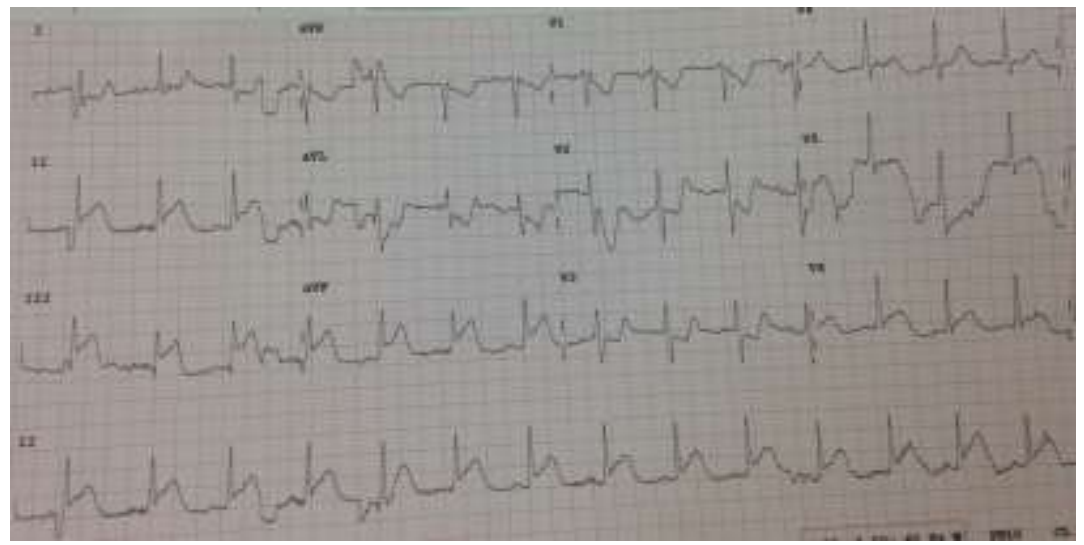


The blood analysis shows a slight elevation of Troponin T US (peak value $250 \mathrm{pg} / \mathrm{ml}$ ). A transthoracic echocardiogram was performed in the acute phase, which showed hypokinesis of the inferior face of the Left Ventricle. The rest of the complementary tests, including chest X-ray, were normal. In the emergency department, the diagnosis of acute myocardial infarction was raised, probably related to a severe allergic reaction (Kounis syndrome). Given the allergic shock, he was treated with fluid therapy, steroids, and antihistamines, and the symptoms quickly resolved. Despite this, precordial tightness was maintained, together with the alterations described in the ECG, and the patient was treated with intravenous nitrates without improvement for 45 minutes, for which it was necessary to administer systemic fibrinolysis with tenecteplase, the symptoms releasing and the ECG normalizing at 5 minutes (PICTURE 2). Emergent coronary angiography was performed (PICTURE 3), which showed a slightly atheromatous coronary tree, but without angiographic lesions or a remaining lysed intracoronary thrombus. The patient was discharged from hospital two days later, recovering normal contractility in all LV segments.

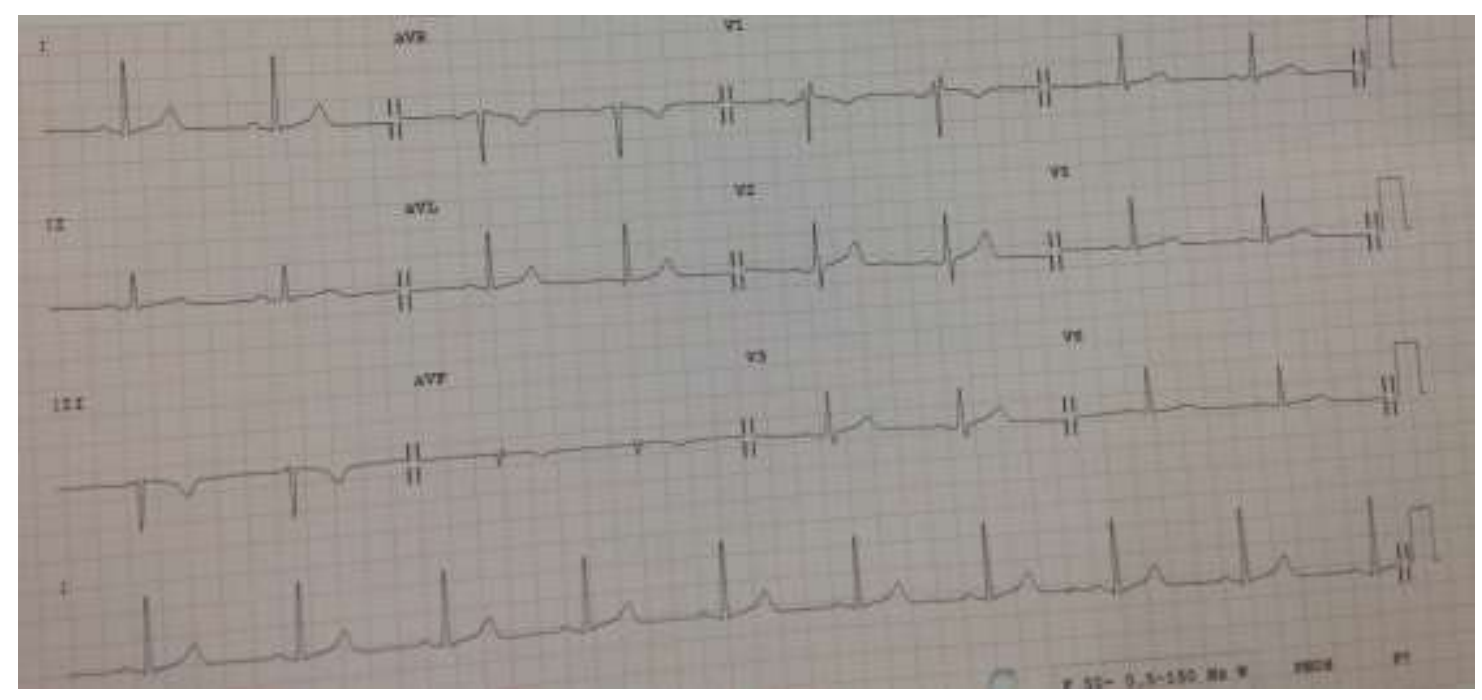

Figure 2: ECG without chest pain

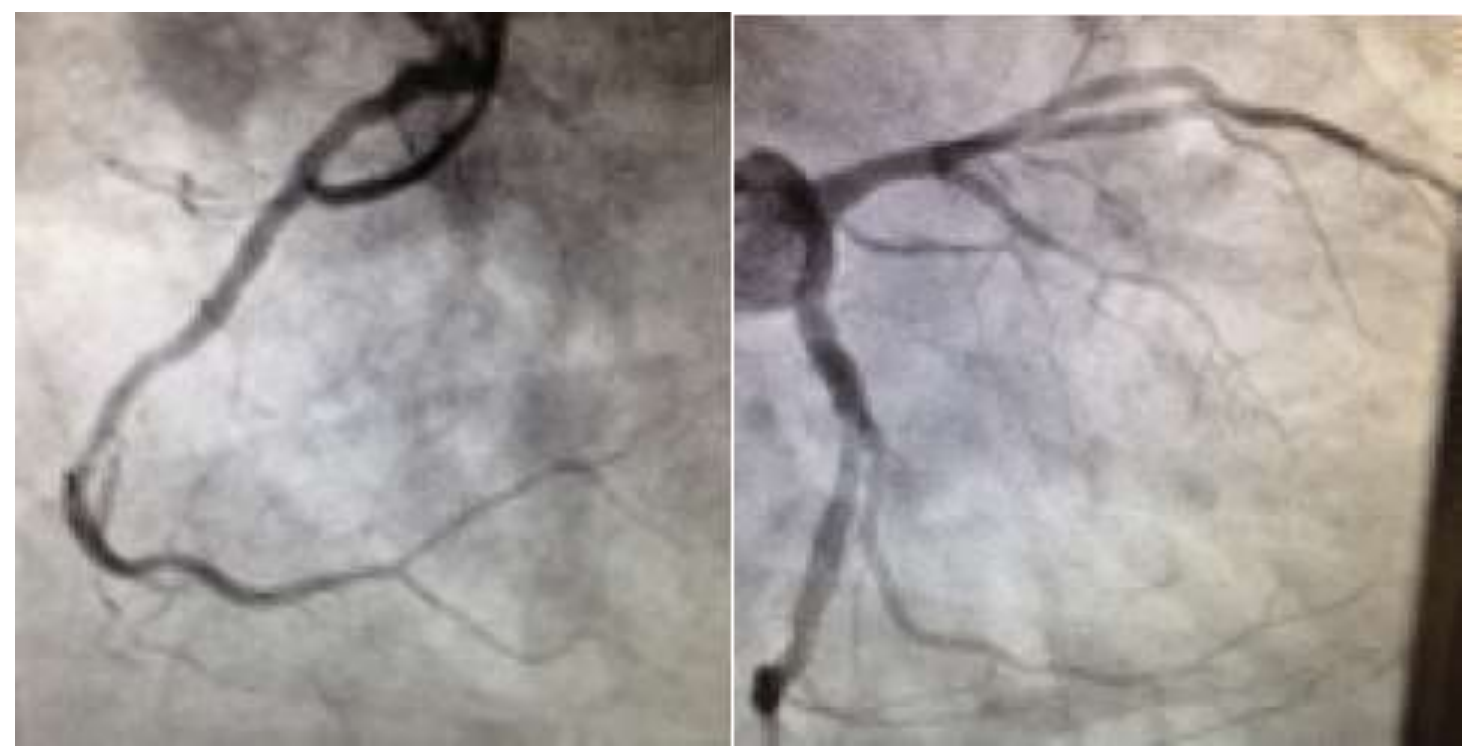

Figure 3: Coronary angiography 
Acute myocardial infarction (AMI) occurs as a consequence of the rupture of an atheroma plaque with the consequent adhesion of a thrombus [1], but we must know that sometimes AMI occurs for other causes, with different pathophysiological processes, that do not require antiplatelet therapy (stress cardiomyopathy , Emboligenic AMI, myocarditis, coronary spasm ...).

Kounis syndrome, also known as allergic angina syndrome, was first described in 1991 by Kounis and Zavras [2]. It is "the concurrence of chest pain and allergic reactions, accompanied by clinical and laboratory findings of classical angina pectoris caused by inflammatory mediators released during the allergic insult", caused by inflammatory mediators released mainly from activated mast cells. The actual incidence of Kounis syndrome is yet to be determined. On an analysis of adverse drug-related events through, 51 cases of Kounis Syndrome were reported during the period of 2010-2014 [3]. An increase in the number of cases of Kounis syndrome is expected in the future as more physicians become aware of the condition.

KS should be kept in mind especially when diagnosing patients without $\mathrm{CV}$ risk factors and pre-existing CVD who experience acute coronary syndrome and report ingestion of a drug accompanied by symptoms of anaphylaxis [4]. Three variants have been described [5]; Type I includes normal coronary arteries without risk factors for $\mathrm{CAD}$, and with the acute release of inflammatory mediators that may induce coronary artery spasm with or without cardiac enzymes elevation and subsequent myocardial infarction. Type II, , which our patient most likely had, includes culprit but quiescent preexisting atheromatous disease in which the acute release of inflammatory mediators may induce coronary artery spasm with or without associated plaque erosion or rupture manifesting as acute myocardial infarction. Type III includes coronary artery stent thrombosis in which aspirated thrombus specimens stained demonstrate the presence of eosinophils and mast cells.

Several pathophysiological mechanisms have been described to explain the involvement of the heart in anaphylactic reactions. The main pathophysiological mechanism is vasospasm of epicardial coronary arteries due to increased inflammatory mediators that are released during a hypersensitivity reaction [6]. The existence of mastocytes in heart tissue and their participation in the anaphylactic reaction that triggers coronary vasoconstriction, dysfunctional ventricular contractility and blockade of atrioventricular conduction is well known. These abnormalities are attributed to the release of inflammatory mediators such as histamine, thrombin, prostaglandins, leukotrienes and platelet activation factors, as well as the release of rennin during episodes of anaphylaxis and its involvement [7].

The initial treatment of these patients requires the administration of intravenous steroids, antihistamines, and fluid replacement, as in our patient. In some cases, depending on the magnitude and extent of the allergic reaction, epinephrine, oxygen, and antithrombotics might be required prior to taking the patient for a coronary angiogram. These initial interventions are primarily intended not only to suppress the allergic reaction but also to dilate the coronary arteries. The latter is mainly accomplished using vasodilators such as nitrates and calcium channel blockers [8]. It is important to be reminded that morphine, a drug commonly used to treat patients presenting with acute coronary artery syndromes, should be avoided in KS, as it may potentially stimulate histamine release and exacerbate the pathologic cascade paradoxically worsening the acute event. Similarly, beta-blockers should also be avoided in this setting if KS is highly suspected as it also may potentiate coronary vasospasm due to an unopposed alpha-adrenergic action. When epinephrine is used for the acute treatment of anaphylaxis, careful monitoring is indicated as epinephrine may potentially worsen coronary vasospasm, aggravating coronary ischemia in KS patients [9].

This case provides two aspects as original and interesting for daily clinical practice: it is a little-known and probably underdiagnosed entity; In addition, the clinical picture resolved with systemic fibrinolysis; Therefore, we cannot be sure if it was a casual or causal relationship, since in the early coronary angiography there were no data of lysed thrombus, which makes us wonder if it was a coronary spasm associated or not with coronary intraluminal thrombus. It would have been important to perform intracoronary imaging techniques to ensure the diagnosis.

All authors confirm that they have made substantial contributions to all of the following: the conception and design of the study, or the acquisition of data, or the analysis and interpretation of the data, the writing and review of the article critically for important intellectual content and contribute in the final version presented.

\section{CONFLICT OF INTEREST}

Funding: None declared

Conflict of Interest: None declared

Contributorship Statement JMG is responsible for the overall content as guarantor. The contributions of each author are as follows: all authors have participated in the authorship of the article in the same way

Consent for publication: Not applicable: The manuscript does not contain any identifying images or information.

Availability of data and material: Please contact Corresponding Author

\section{REFERENCES}

1. Badimon L, Padró T, Vilahur G. Atherosclerosis, platelets and thrombosis in acute ischaemic heart disease. Eur Heart J Acute Cardiovasc Care. 2012 Apr;1(1):60-74. doi: 10.1177/2048872612441582. PMID: 24062891; PMCID: PMC3760546.

2. Kounis NG, Zavras GM. Histamine-induced coronary artery spasm: the concept of allergic angina. Br J Clin Pract. 1991 Summer;45(2):121128. PMID: 1793697.

3. Renda F, Landoni G, Trotta F, et al. Kounis Syndrome: An analysis of spontaneous reports from international pharmacovigilance database. Int $J$ Cardiol. 2016;203:217-220. doi:10.1016/j.ijcard.2015.10.003.

4. Gázquez V, Dalmau G, Gaig P, Gómez C, Navarro S, Mercé J. Kounis syndrome: report of 5 cases. J Investig Allergol Clin Immunol. 2010;20(2):162-5. PMID: 20461972.

5. Kounis NG, Mazarakis A, Tsigkas G, Giannopoulos S, Goudevenos J. Kounis syndrome: A new twist on an old disease. Future Cardiol. 2011;7:805-824.

6. Kounis NG, Zavras GM. Allergic angina and allergic myocardial infarction. Circulation. 1996 Oct 1;94(7):1789. PMID: 8840881. 
7. Gangadharan V, Bhatheja S, Al Balbissi K. Kounis syndrome - an atopic monster for the heart. Cardiovasc Diagn Ther. 2013 Mar;3(1):47-51. doi: 10.3978/j.issn.2223-3652.2013.02.04. PMID: 24282744 ; PMCID: PMC3839223.

8. Cevik C, Nugent K, Shome GP, Kounis NG. Treatment of Kounis syndrome. Int J Cardiol. 2010
Sep

3;143(3):223-6.

doi:

10.1016/j.ijcard.2010.02.040. Epub 2010 Mar 4. PMID: 20206392.

9. Kounis NG. Coronary hypersensitivity disorder: the Kounis syndrome. Clin Ther. 2013 May;35(5):563571. doi: 10.1016/j.clinthera.2013.02.022. Epub 2013 Mar 13. PMID: 23490289.
This work is licensed under Creative Commons Attribution 4.0 License

To Submit Your Article Click Here: Submit Manuscript

DOI:10.31579/2641-0419/175
Ready to submit your research? Choose Auctores and benefit from:

* fast, convenient online submission

* rigorous peer review by experienced research in your field

* rapid publication on acceptance

* authors retain copyrights

* unique DOI for all articles

* immediate, unrestricted online access

At Auctores, research is always in progress.

Learn more www.auctoresonline.org/journals/clinical-cardiology-andcardiovascular-interventions 